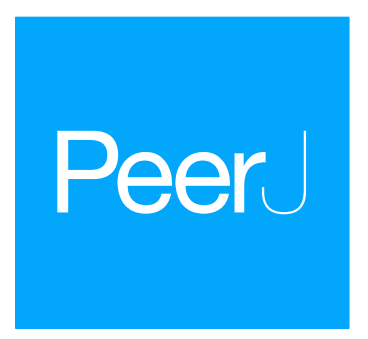

Submitted 4 February 2017

Accepted 8 September 2017

Published 24 October 2017

Corresponding author

Juliana Tuller,

julianatullerm@gmail.com

Academic editor

Brenda Oppert

Additional Information and Declarations can be found on page 11

DOI 10.7717/peerj.3864

Copyright

2017 Tuller et al.

Distributed under

Creative Commons CC-BY 4.0

OPEN ACCESS

\section{Glycaspis brimblecombei (Hemiptera: Psyllidae) attack patterns on different Eucalyptus genotypes}

\author{
Juliana Tuller ${ }^{1}$, Karla Nunes Oliveira ${ }^{2}$, Jhonathan Oliveira Silva ${ }^{3}$, \\ Maurício Lopes de Faria ${ }^{4}$, Mario Marcos do Espírito-Santo ${ }^{4}$, \\ José Eduardo Serrão ${ }^{5}$ and José Cola Zanuncio ${ }^{5}$ \\ ${ }^{1}$ Departmento de Biologia, Setor de Ecologia e Conservação, Universidade Federal de Lavras (UFLA), Lavras, \\ Minas Gerais, Brazil \\ ${ }^{2}$ Pós-Graduação em Ecologia, Departamento de Biologia Geral, Universidade Federal de Viçosa, Viçosa, \\ Minas Gerais, Brazil \\ ${ }^{3}$ Colegiado de Ecologia, Universidade Federal do Vale do São Francisco (UNIVASF), Senhor do Bonfim, \\ Bahia, Brazil \\ ${ }^{4}$ Departamento de Biologia Geral, Universidade Federal de Viçosa (UFV), Viçosa, Minas Gerais, Brazil \\ ${ }^{5}$ Departamento de Entomologia/BIOAGRO, Universidade Federal de Viçosa (UFV), Viçosa, \\ Minas Gerais, Brazil
}

\section{ABSTRACT}

Background. The red gum lerp psyllid, Glycaspis brimblecombei Moore (Hemiptera: Psyllidae), an eucalypt insect pest from Australia, was reported in Brazil in 2003. This study evaluated damage patterns of this pest on Eucalyptus camaldulensis Dehn (Myrtaceae) and its hybrids E. urophylla X E. camaldulensis (urocam) and E. urophylla $\mathrm{X}$ E. grandis (urograndis). In addition, parasitism rates of Psyllaephagus bliteus Riek (Hymenoptera: Encyrtidae) on G. brimblecombei collected on different eucalypt genotypes are reported.

Methods. Plantation plots of three eucalypt genotypes were evaluated over one year. The eucalypt leaves were collected and examined for attack by G. brimblecombei. Nymph parasitism of G. brimblecombei by P. bliteus was recorded.

Results. Damage by G. brimblecombei was lower on the hybrid genotypes and on the adaxial surface of the eucalypt leaves. G. brimblecombei egg and nymph density were negatively correlated with monthly rainfall. Nymph parasitism of G. brimblecombei by P. bliteus was low (2.9\%) independent of genotype and did not vary throughout the year. Discussion. Our data indicate the use of less susceptible eucalypt genotypes (e.g., hybrids) as an alternative to G. brimblecombei management. Because of the current low mortality rates for G. brimblecombei resulting from P. bliteus parasitism, biological control with this natural enemy is not recommended as a management strategy for G. brimblecombei.

Subjects Agricultural Science, Entomology, Plant Science

Keywords Hybrid eucalypt, Biological control, Psyllaephagus bliteus, Red gum lerp psyllid, Water stress

\section{INTRODUCTION}

The Australian genus Eucalyptus includes some of the most cultivated plants around the world. In Brazil, this genus was introduced in the second half of the 19th century 
(Couto \& Betters, 1995), and its plantations cover more than 4.8 million ha (ABRAF, 2013). The Eucalyptus genus comprises more than 600 species (not including hybrids) with more than 30 species cultivated in Brazil (Queiroz, Burckhardt \& Majer, 2012) for cellulose, charcoal, essential oils, furniture, planks, and paper production. Eucalyptus has a remarkable native and exotic phytophagous fauna in Brazil (Guedes et al., 2000), which can be explained by the suitable climatic conditions and its phylogenetic proximity to the Brazilian flora, with high Myrtaceae diversity (Zanuncio et al., 2001).

Exotic phytophagous insects causing economic losses in Brazilian eucalypt plantations (Pereira et al., 2001) include the blue gum lerp psyllid Ctenarytaina eucalypti (Hemiptera: Psyllidae), the eucalyptus snout beetles Gonipterus gibberus and G. scutellatus, the Australian eucalyptus longhorn Phoracantha semipunctata (Coleoptera: Cerambycidae) (Ribeiro et al., 2001; Queiroz-Santana \& Burckhardt, 2007), the eucalyptus gall wasp Leptocybe invasa (Hymenoptera: Eulophidae) (Fernandes et al., 2014), and the Australian red gum lerp psyllid, Glycaspis brimblecombei Moore (Hemiptera: Psyllidae) (Ferreira-Filho et al., 2015). G. brimblecombei is the major problem in eucalypt plantations in Brazil and was first recorded in São Paulo State in 2003 (Wilcken et al., 2003), spreading quickly throughout the country (Pereira et al., 2013; Queiroz et al., 2013). Because G. brimblecombei can cause $20 \%$ to $30 \%$ of defoliation, crown thinning, and eucalypt mortality (Wilcken et al., 2003; Queiroz et al., 2013), there is an urgent need to develop strategies aiming to manage this pest in Brazil.

G. brimblecombei reproduces sexually, depositing 6-45 eggs per eucalypt leaf, preferentially on young leaves (Firmino-Winckler et al., 2009). Psyllid nymphs produce honeydew after initial feeding and use it with a wax secretion to build tapered protective white shelters (lerp) on the leaf surface (Sharma et al., 2013). G. brimblecombei has five nymph instars, with a complete lifecycle from 15 to 34 days, and several generations per year (FirminoWinckler et al., 2009; Laudonia, Magiotta \& Sasso, 2014). There are no records of diapause for this psyllid species, even during the winter in temperate countries (FAO, 2012; Laudonia, Magiotta \& Sasso, 2014). In its original habitat in Australia, G. brimblecombei prefers to feed on E. camaldulensis Dehn (Myrtaceae) and natural enemies, such as parasitoids and predators, exert strong control of psyllid populations (Collett, 2001).

Integrated pest management (IPM) combines different control methods, such as physical, chemical (Zanetti et al., 2003), cultural, and biological methods (Grosman et al., 2005) to reduce pest damage (Kogan, 1998). However, IPM efficiency depends on understanding the pest lifecycle, susceptibility to environmental conditions, female preference and offspring performance on host plants and habitats, population dynamics, and mortality from natural enemies (VanLenteren et al., 2003; Lockwood \& Gilroy, 2004; Pereira et al., 2013). Chemical control has low efficacy against G. brimblecombei (Queiroz-Santana \& Burckhardt, 2007), but entomopathogenic fungi (DalPogetto et al., 2011), predators (Dias et al., 2012; Dias et al., 2014), and its main natural enemy from Australia, the parasitoid Psyllaephagus bliteus Riek (Hymenoptera: Encyrtidae), have been studied to manage this insect (Daane et al., 2005; Daane, Sime \& Paine, 2012).

P. bliteus is a koinobiont parasitoid that prefers to oviposit on third-instar G. brimblecombei nymphs, but its offspring development is delayed until the psyllid 
reaches the fifth instar (Daane et al., 2005). The exoskeleton of the dead parasitized hosts forms an easily recognized mummy, and the psyllid nymph is completely consumed as the parasitoid nearly finishes development. The white P. bliteus larva can be seen throughout the mummified exoskeleton of G. brimblecombei, which becomes transparent (Sullivan et al., 2006). P. bliteus was accidentally introduced into Brazil and was first reported soon after its host in 2003 (Berti-Filho et al., 2003). Due to the low level of natural parasitism $(0.2-11 \%)$ and to the reported success of this parasitod in controlling G. brimblecombei in the United States and Mexico, a program aimed at rearing and mass release of $P$. bliteus was started in Brazil (Ferreira-Filho et al., 2015). In Brazil, areas under this augmentative biological control showed a temporary increase in the parasitism rate of G. brimblecombei by $P$. bliteus up to $80 \%$, although viable parasitoid populations were not found, requiring frequent releases (Ferreira-Filho et al., 2015).

The low long-term efficiency of $P$. bliteus to control G. brimblecombei through mass release programs indicate that integrative approaches are necessary, and the use of resistant eucalypt genotypes can be an alternative to pesticides for insect management. Hybrid eucalypt plants were developed for greater commercial value (such as wood density for furniture and construction and lignin content for charcoal) or increasing resistance to water stress and pests (Gonçalves et al., 2013). The susceptibility of Eucalyptus genotypes to insect species varies (Firmino-Winckler et al., 2009; Queiroz, Burckhardt \& Majer, 2012) and plant mechanisms responsible for reducing damages by these organisms must be further investigated. Given that both temperature (Ferreira-Filho et al., 2015) and rainfall (Oliveira et al., 2012) affect G. brimblecombei abundance, further studies are necessary to determine of correct time of management interventions.

The present study aimed to evaluate the temporal and spatial patterns of abundance of G. brimblecombei on Eucalyptus camaldulensis and the hybrids E. urophylla X E. camaldulensis ("Urocam") and E. urophylla X E. grandis ("Urograndis"), as well as the parasitism of this psyllid by the wasp P. bliteus, the following questions were addressed: (i) Do the densities of G. brimblecombei eggs and nymphs vary according to the host plant type, leaf surface (abaxial versus adaxial) and period of the year? (ii) Does the parasitism rate of $G$. brimblecombei nymphs by $P$. bliteus vary according to the aforementioned factors? (iii) Is the temporal variation of G. brimblecombei related to the amount of rainfall?

\section{MATERIALS AND METHODS}

\section{Study area}

The study was conducted at Extrema farm $\left(17^{\circ} 15^{\prime} \mathrm{S} 43^{\circ} 39^{\prime} \mathrm{W}\right)$, which is owned and managed by Vallourec \& Mannesman Florestal S.A. in Olhos D’Água, Minas Gerais State, Brazil. This farm is located at an altitude of $800 \mathrm{~m}$ above sea level and has an area of 9,655.61 ha, of which 6,597.72 ha (68\%) are planted with several different species and hybrids of Eucalyptus, and $1,884.22$ ha $(32 \%)$ are native vegetation remnants (mostly Cerrado fragments). This region has a tropical climate, with a dry season from June to September (Aw in Köppen's classification), and a rainy season from November to March. The mean annual temperature is $24^{\circ} \mathrm{C}$ and the total annual rainfall is $1,246 \mathrm{~mm}$, according to data collected at a weather 
station at the Extrema farm. The selected plots had six year-old individuals of the river red gum E. camaldulensis Dehn, and two hybrids: E. urophyla $\times$ E. camaldulensis (urocam) and E. urophyla $\times$ E. grandis (urograndis).

\section{Sampling}

Sampling was conducted in two plots per eucalypt plant genotype (E. camaldulensis, urocam and urograndis). Twenty eucalypt trees were randomly selected each month, from December 2006 to November 2007, and 10 leaves were collected per tree were individually bagged and taken to the laboratory. The number of G. brimblecombei eggs and nymphs at each instar were recorded for both the abaxial and adaxial leaf surfaces. The percentage of mortality inflicted by P. bliteus parasitism was calculated for nymphs between the third and the fifth instars by the following formula: (number of parasitized nymphs / total number of nymphs)* 100 . The viability of G. brimblecombei eggs was determined using the percentage of hatched eggs. After the insects were counted and removed, each leaf was scanned and its area was determined using the Image J software (Rasband, 2006). The density of G. brimblecombei eggs and nymphs per $\mathrm{cm}^{2}$ was determined for each leaf, and their mean densities were calculated per tree.

\section{Statistical analyses}

Linear mixed effect models (LME) were constructed to determine the influence of Eucalyptus genotypes, leaf surface and time (explanatory variables) on the densities of G. brimblecombei eggs and nymphs and on the percentage of nymphs parasitized by $P$. bliteus (response variables). The effects of leaf surface on nymph density were only analyzed for E. camaldulensis because the number of nymphs was very low on urocam (45) and urograndis (48) genotypes. These models (one for each response variable) were tested against null models and followed by residual inspection of the error distribution. The LME models were used owing to random effects (Crawley, 2007), such as the nested structure of the data into different Eucalyptus genotypes/leaf surface. Time was only included as an explanatory variable in the models for E. camaldulensis because of the low density of G. brimblecombei on the two hybrid genotypes. Generalized linear models (GLM; one per response variable) were employed to test the influence of average monthly rainfall on the density of G. brimblecombei eggs and nymphs and on the percentage of nymphs parasitized by $P$. bliteus.

The non-significant variables were progressively (one-by-one) removed with the backward method, starting from the complete models containing all explanatory variables and their interactions until the minimal adequate models were obtained (Crawley, 2007). After this procedure, the differences between the levels of all categorical variables were tested with contrast analyses. All the models were also tested for the adequacy of the error distribution through residual analysis. The analyses were conducted with the software $\mathrm{R}$ version 2.14 ( $R$ Development Core Team, 2011).

\section{RESULTS}

A total of 481,212 eggs and 42,785 nymphs of G. brimblecombei were found on 14,388 eucalypt leaves. Egg and nymph densities were significantly higher on E. camaldulensis 
Table 1 Statistical parameters for the analyses evaluating G. brimblecombei attack patterns and its parasitism by Psyllaephagus bliteus on different Eucalyptus genotypes and leaf surfaces along twelve months. The effects of rainfall on monthly variations on psyllid egg and nymph density were also tested.

\begin{tabular}{|lllll} 
Response variable & Explanatory variable & $\boldsymbol{n}$ & $\boldsymbol{F}$ & $\boldsymbol{P}$ \\
\hline Egg density & Eucalyptus genotype & 1,140 & 537.90 & $<0.001$ \\
Nymph density & Eucalyptus genotype & 1,140 & 250.00 & $<0.001$ \\
Percentage of parasitized nymphs & Eucalyptus genotype & 1,140 & 0.24 & 0.665 \\
\hline Egg density on E. camaldulensis & Leaf surface & 480 & 21.77 & $<0.001$ \\
\hline Egg density on urograndis & Leaf surface & 480 & 0.83 & 0.363 \\
Egg density on urocam & Leaf surface & 480 & 0.02 & 0.878 \\
\hline Nymph density E. camaldulensis & Leaf surface & 480 & 0.72 & 0.464 \\
\hline Egg density on E. camaldulensis & Time (month) & 1,440 & 51.49 & $<0.001$ \\
Nymph density on E. camaldulensis & Time (month) & 1,440 & 85.57 & $<0.001$ \\
\hline Percentage of parasitized nymphs & Time (month) & 1,440 & 1.47 & 0.128 \\
Egg density on E. camaldulensis & Monthly rainfall & 12 & 67.43 & $<0.001$ \\
Nymph density on E. camaldulensis & Monthly rainfall & 12 & 83.48 & $<0.001$ \\
\hline
\end{tabular}

compared to the hybrids urograndis and urocam (Table 1; Fig. 1). Egg density also was higher on the abaxial surface of E. camaldulensis and urograndis, although this difference was only significant for E. camaldulensis $(p<0.001)$ (Fig. 1; Table 1$)$. However, nymph density did not differ between surfaces for E. camaldulensis ( $p>0.05)$. G. brimblecombei egg viability was $4 \%, 2 \%$ and $1 \%$ on E. camaldulensis, urocam and urograndis, respectively.

We found 976 nymphs of G. brimblecombei parasitized by P. bliteus on E. camadulensis, but the mortality caused by this parasitoid was low (2.28\%). Only one and two nymphs were parasitized on urograndis $(2.08 \%)$ and urocam $(4.44 \%)$, respectively, because the availability of 3-5th instar P. bliteus nymphs on these genotypes was very low (Fig. 1B).

G. brimblecombei attacks on E. camaldulensis varied throughout the year, with egg and nymph densities of this insect peaking during the dry season (May to October) and decreasing in the rainy season (December to March) (Table 1; Fig. 2). Egg and nymph density were negatively correlated with monthly rainfall (Table 1; Fig. 3).

\section{DISCUSSION}

We detected marked spatial and temporal patterns of attack in different Eucalyptus genotypes by G. brimblecombei during the study period. Both the preference (as indicated by egg density) and performance (percentage of eggs hatched) were higher on E. camaldulensis than hybrids. At a finer scale, psyllid females preferred to lay their eggs on the abaxial surface of eucalypt leaves. The strong temporal variation on the abundance of G. brimblecombei highlights the susceptibility of this insect to climatic conditions. These results, coupled with the with low parasitism rates by $P$. bliteus detected in this psyllid population, can improve IPM strategies for a more effective control of G. brimblecombei on eucalypt plantations. 

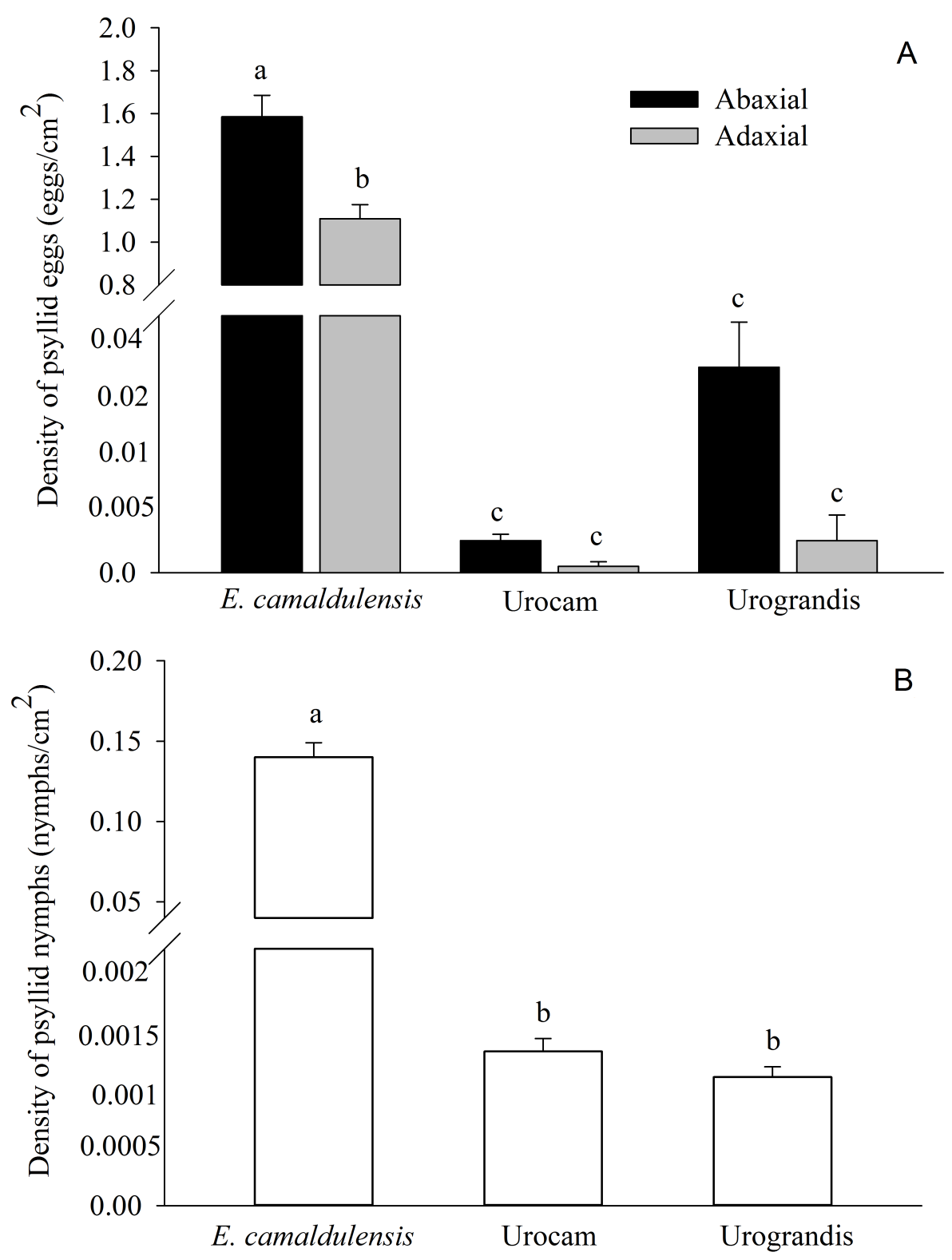

Eucalypt genotypes

Figure 1 Mean density of (A) Glycaspis brimblecombei eggs on leaf surfaces of different eucalypt genotypes. (B) Mean density of G. brimblecombei nymphs (white columns) on leaves of different eucalypt genotypes. Error bars indicate standard errors. Different letters above the bars indicate statistically significant differences $(\alpha=0.05)$.

Full-size DOI: 10.7717/peerj.3864/fig-1

The higher E. camaldulensis susceptibility to the red gum lerp psyllid corroborates the field and laboratory studies on this pest in Brazil (Wilcken et al., 2003; Pereira et al., 2013) and other parts of the world (Wilcken et al., 2003; Valente \& Hodkinson, 2009). The oviposition preference of G. brimblecombei females for E. camaldulensis is linked to higher egg viability and nymph survival on this eucalypt species (Firmino-Winckler et al., 2009). 

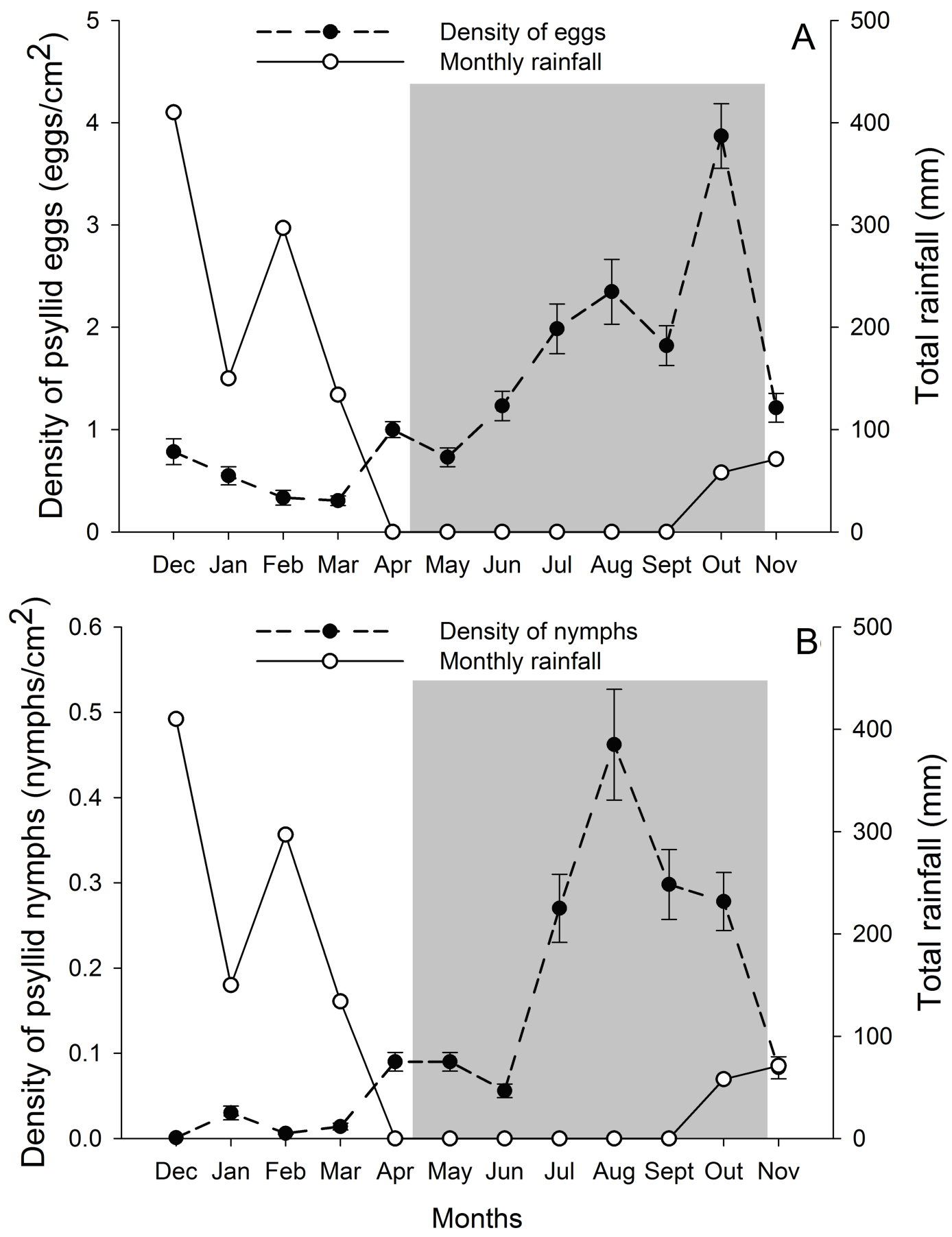

Figure 2 Monthly total rainfall and temporal variation on the mean number of G. brimblecombei eggs (A) and nymphs (B) on E. camaldulensis from December 2006 to November 2007. Error bars indicate standard errors. The shaded area indicates the dry season.

Full-size DOI: 10.7717/peerj.3864/fig-2 

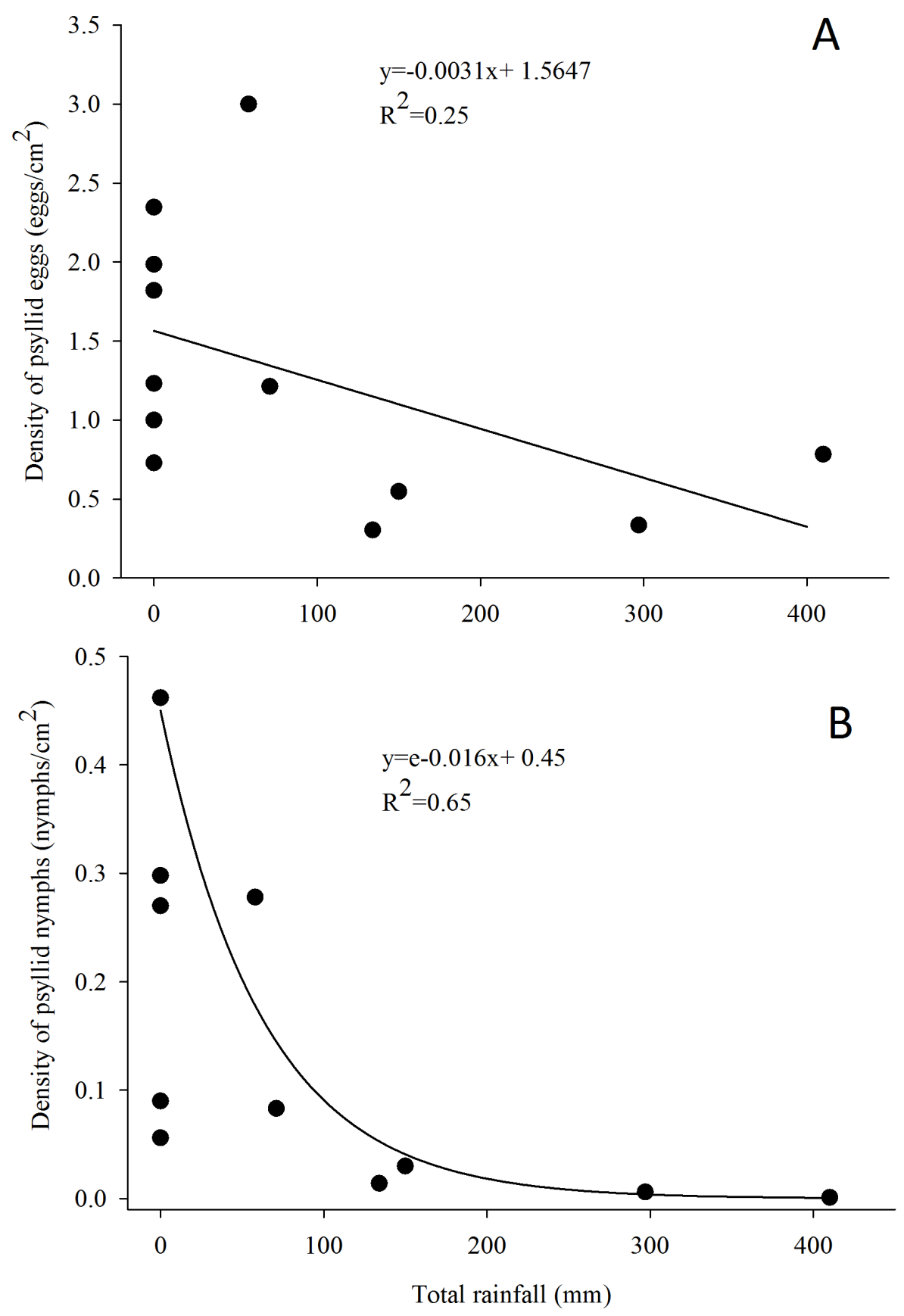

Figure 3 Relationship between the density of G. brimblecombei eggs (A) and nymphs (B) on E. camaldulensis and monthly total rainfall $(n=12)$. The estimated parameters were used to fit the curve obtained with the minimal adequate GLM model, in order to adjust linear and exponential functions in figures (A) and (B), respectively.

Full-size DOI: $10.7717 /$ peerj.3864/fig-3 
Nevertheless, the mechanisms responsible for such differential preference and performance between E. camaldulensis and hybrid lineages are still poorly studied. One hypothesis is that the long coexistence of E. camaldulensis and G. brimblecombei in Australia (Phillips, 1992) favors the successful attack on the natural genotype, possibly because this insect evolved the capacity to deal with chemical and physical defenses of E. camaldulensis leaves. Thus, studies involving leaf morphology and physiology are needed to identify the resistance mechanism of hybrid Eucalyptus genotypes for G. brimblecombei. Interspecific and phenotypic differences on leaf traits (e.g., texture, roughness, and trichome density) occur between Eucalyptus genotypes (Reifenrath, Riederer \& Müller, 2005) and may play an important role in psyllid preference and performance, especially affecting the adhesion of first-instar nymphs to the leaf surface. Higher lerp abundance and lower G. brimblecombei nymph and adult mortality on E. globulus leaves were observed when epicuticular wax was removed (Brennan \& Weinbaum, 2001a). The amount of epicuticular wax varies among Eucalyptus genotypes and is important for reducing the adhesion of psyllid nymphs (Brennan \& Weinbaum, 2001a) and stylet probing (Brennan \& Weinbaum, 2001b) on waxy, resistant eucalypt leaves.

As a whole, females preferred to oviposit on the abaxial surface of the three eucalypt genotypes, although statistically significant differences were only detected for E. camaldulensis. This pattern was already observed in previous studies with G. brimblecombei (FirminoWinckler et al., 2009; Oliveira et al., 2012) and was explained by the higher nutrient flow for nymph development and reduced desiccation on the abaxial surface, especially during insect molt (Phillips, 1992; Firmino-Winckler et al., 2009). Thus, a preference-performance link would be expected, with higher nymph density on the abaxial surface. This was not the case for E. camaldulensis, but the underlying mechanisms are yet to be determined. Since parasitism levels did not differ between leaf surfaces, it is possible that first-instar nymphs emerging from eggs on the abaxial surface migrate to the adaxial surface to reduce intraspecific competition. Observational studies on nymph behavior would help understand this small-scale distribution pattern of G. brimblecombei on E. camaldulensis.

The low parasitism levels of G. brimblecombei by P. bliteus observed in our site corroborate other studies under natural conditions conducted in Brazil (0.2-11\%; FerreiraFilho et al., 2015) and United States (1.67-33\%; Daane, Sime \& Paine, 2012). In several countries, rearing and mass release of $P$. bliteus showed promising results, increasing parasitism levels in the field up to 94\% (Huerta, Faundez \& Araya, 2010; Ferreira-Filho et al., 2015). However, this parasitoid failed to establish viable populations in regions of warm climate, such as some parts of California (Daane, Sime \& Paine, 2012) and in Brazil (Ferreira-Filho et al., 2015). Thus, it is likely that an effective control of G. brimblecombei using P. bliteus would demand periodic mass releases, increasing the financial costs of this strategy.

The peak in the egg and nymph density of G. brimblecombei on E. camaldulensis during the dry season corroborates other studies conducted for this species in Brazil (Wilcken et al., 2003; Ferreira-Filho et al., 2015). Several studies conducted with G. brimblecombei in other countries indicate that temperature is the main factor involved in population dynamics of this psyllid (Paine, Millar \& Hoddle, 2000; Ramirez, Mancera \& Guerra-Santos, 2003; 
Laudonia, Magiotta \& Sasso, 2014). Under laboratory conditions in Brazil, Firmino found that $26{ }^{\circ} \mathrm{C}$ is the optimal temperature for the development and reproduction of G. brimblecombei. Thus, in our study site, the temperature was adequate for this species during the entire year and was likely not driving temporal variations in the abundance of G. brimblecombei. Instead, our results clearly indicate a strong effect of rainfall on the egg and nymph density, a pattern already described for G. brimblecombei in Mexico (Ramirez, Mancera \& Guerra-Santos, 2003) and Mauritius Islands (Sookar, Seewooruthun \& Ramkhelawon, 2003). Furthermore, a controlled experiment of rainfall simulation showed that the mechanical removal of the psyllid lerps by water droplets and/or lerp solubilization by leaf moisture may decrease its population (Oliveira et al., 2012). In addition, the higher humidity during the rainy season increases entomopathogenic fungi occurrence, which may kill psyllid nymphs (Ramirez, Mancera \& Guerra-Santos, 2003). Long-term studies are needed to confirm the temporal pattern described here and assess other potential mechanisms driving the abundance of G. brimblecombei, such as physiological changes induced by water stress during the dry season.

This is one of the few studies addressing spatial and temporal patterns of abundance of G. brimblecombei and its levels of mortality using multiple eucalypt genotypes under field conditions. Despite the temporal variations on psyllid density and need for confirmation through long-term sampling, our one-year study is the longest conducted until now with this species, and confirms other results that indicate the higher abundance of G. brimblecombei during the dry season in Brazil. Thus, management strategies should consider the synchronization of planting with the rainy season to avoid the exposition of susceptible saplings of Eucalyptus spp. to severe attack by G. brimblecombei. Our findings indicate that using resistant Eucalyptus hybrids such as urocam and urograndis is a better management option than relying on P. bliteus to control the damage caused by the psyllid, due to its low parasitism levels. Studies aimed at determining leaf traits correlated to hybrid resistance to G. brimblecombei are necessary to select other commercially viable eucalypt genotypes or to enhance these traits through genetic improvement of susceptible species.

\section{ACKNOWLEDGEMENTS}

We thank Vallourec \& Mannesman SA for the logistical support, especially from Josefredo D. Moreira, Vilmar de A. Izidoro and Bianca V. Fernandes. We thank Fabiene M. de Jesus, Ronald R.M. Santos and Sarah F.M. Silva for the help during field and lab work. Thais G. Pellegrini made valuable suggestions to the early drafts of this manuscript. This paper was partially produced during the course PEC 527 - Publicação Científica of the Graduate Program in Applied Ecology of the Universidade Federal de Lavras. Dr. Phillip Villani revised and corrected the English language used in this manuscript. 


\section{ADDITIONAL INFORMATION AND DECLARATIONS}

\section{Funding}

This study was supported by Fundação de Amparo à Pesquisa do Estado de Minas Gerais (FAPEMIG - Process EDT-318/05), Conselho Nacional de Desenvolvimento Científico e Tecnológico (CNPq), Coordenação de Aperfeiçoamento de Pessoal de Nível Superior (CAPES) and Programa de Proteção Florestal (PROTEF) from the Instituto de Pesquisas e Estudos Florestais (IPEF). FAPEMIG provided a scholarship to Karla N. Oliveira (ProbicFAPEMIG), Jhonathan de O. Silva (Bic-UNIMONTES) and Mário Marcos do EspíritoSanto (BIPDT-FAPEMIG). The funders had no role in study design, data collection and analysis, decision to publish, or preparation of the manuscript.

\section{Grant Disclosures}

The following grant information was disclosed by the authors:

Fundação de Amparo à Pesquisa do Estado de Minas Gerais (FAPEMIG - Process EDT318/05).

Conselho Nacional de Desenvolvimento Científico e Tecnológico (CNPq).

Coordenação de Aperfeiçoamento de Pessoal de Nível Superior (CAPES).

Instituto de Pesquisas e Estudos Florestais (IPEF).

FAPEMIG.

\section{Competing Interests}

The authors declare there are no competing interests.

\section{Author Contributions}

- Juliana Tuller performed the experiments, analyzed the data, contributed reagents/materials/analysis tools, wrote the paper, prepared figures and/or tables, reviewed drafts of the paper.

- Karla Nunes Oliveira and Jhonathan Oliveira Silva conceived and designed the experiments, performed the experiments, analyzed the data, contributed reagents/materials/analysis tools, wrote the paper, prepared figures and/or tables, reviewed drafts of the paper.

- Maurício Lopes de Faria and Mario Marcos do Espírito-Santo conceived and designed the experiments, contributed reagents/materials/analysis tools, wrote the paper, reviewed drafts of the paper.

- José Eduardo Serrão and José Cola Zanuncio wrote the paper, reviewed drafts of the paper.

\section{Data Availability}

The following information was supplied regarding data availability:

The raw data has been supplied as Data S1.

\section{Supplemental Information}

Supplemental information for this article can be found online at http://dx.doi.org/10.7717/ peerj.3864\#supplemental-information. 


\section{REFERENCES}

Associação Brasileira de Flautistas (ABRAF). 2013. Anuário estatístico da Associação Brasileira de Produtores de Florestas Plantadas 2013 ano base 2012 [Statistical Yearbook of the Brazilian Association of Planted Forest Producers 2013 base year 2012]. Brasília: ABRAF.

Berti-Filho E, Costa VA, Zuparko RL, LaSalle J. 2003. Occurrence of Psyllaephagus bliteus Riek (Hymenoptera: Encyrtidae) in Brasil. Revista de Agricultura 78(3):304-304.

Brennan EB, Weinbaum SA. 2001a. Effect of epicuticular wax on adhesion of psyllids to glaucous juvenile and glossy adult leaves of Eucalyptus globulus Labillardière. Australian Journal of Entomology 40:270-277 DOI 10.1046/j.1440-6055.2001.00229.x.

Brennan EB, Weinbaum SA. 2001b. Stylet penetration and survival of three psyllid species on adult leaves and 'waxy' and 'de-waxed' juvenile leaves of Eucalyptus globulus. Entomologia Experimentalis et Applicata 100:355-363 DOI 10.1046/j.1570-7458.2001.00883.x.

Collett N. 2001. Biology and control of psyllids, and the possible causes for defoliation of Eucalyptus camaldulensis Dehnh. (river red gum) in south-eastern Australia-a review. Australian Forestry 64(2):88-95 DOI 10.1080/00049158.2001.10676170.

Couto L, Betters DR. 1995. Short-rotation eucalypt plantations in Brazil: social and environmental issues. Oak Ridge: Oak Ridge National Laboratory.

Crawley MJ. 2007. The R book. 1st edition. Chichester: John Wiley \& Sons Ltd.

Daane KM, Sime KR, Dahlsten DL, Andrews-Jr JW, Zuparko RL. 2005. The biology of Psyllaephagus bliteus Riek (Hymenoptera: Encyrtidae), a parasitoid of the red gum lerp psyllid (Hemiptera: Psylloidea). Biological Control 32:228-235 DOI 10.1016/j.biocontrol.2004.09.015.

Daane KM, Sime KR, Paine TD. 2012. Climate and the effectiveness of Psyllaephagus bliteus as a parasitoid of the red gum lerp psyllid. Biocontrol Science and Technology 22:1305-1320 DOI 10.1080/09583157.2012.724383.

DalPogetto MHFA, Wilcken CF, Gimenes MJ, Christovam RS, Prado EP. 2011. Control of red-gum lerp psyllid with formulated mycoinsecticides under semi-field conditions. International Journal of Tropical Insect Science 31(1-2):85-91 DOI 10.1017/S1742758411000166.

Dias TKR, Wilcken CF, Soliman EP, Barbosa LR, Serrão JE, Zanuncio JC. 2014. Predation of Thaumastocoris peregrinus (Hemíptera: Thaumastocoridae) by Atopozelus opsimus (Hemiptera: Reduviidae) in Brazil. Invertebrate Survival Journal 11:224-227.

Dias TKR, Wilcken CF, Soliman EP, Gil-Santana HR, Zaché B. 2012. Occurrence of Atopozelus opsimus preying on nymphs and adults of Glycaspis brimblecombei. Phytoparasitica 40:137-141 DOI 10.1007/s12600-011-0213-1.

FAO. 2012. Glycaspis brimblecombei. Forest pest species profiles. Available at http://www. fao.org/forestry/37414-078b9936edf4b343e8a7afadele0c6bf4.pdf.

Fernandes BV, Barcelos JAV, Andrade HB, Zanuncio JC. 2014. Leptocybe invasa (Hymenoptera: Eulophidae), an exotic pest of Eucalyptus, in Minas Gerais state, Brazil. Florida Entomologist 97(2):824-826 DOI 10.1653/024.097.0270. 
Ferreira-Filho PJ, Wilcken CF, Lima ACV, DeSá LAN, DoCarmo JB, Guerreiro JC, Zanuncio JC. 2015. Biological control of Glycaspis brimblecombei (Hemiptera: Aphalaridae) in eucalyptus plantations. Phytoparasitica 43(2):151-157 DOI 10.1007/s12600-014-0440-3.

Firmino-Winckler DC, Wilcken CF, Oliveira NC, Matos CAO. 2009. Biologia do psilídeo-de-concha Glycaspis brimblecombei Moore (Hemiptera, Psyllidae) em Eucalyptus spp. Revista Brasileira de Entomologia 53(1):144-146

DOI 10.1590/S0085-56262009000100030.

Gonçalves JLM, Alvares CA, Higa AR, Silva LD, Alfenas AC, Stahl J, Ferraz SFB, Lima WP, Brancalion PHS, Hubner A, Bouillet JD, Laclau J, Nouvellon Y, Epron D. 2013. Integrating genetic and silvicultural strategies to minimize abiotic and biotic constraints in Brazilian eucalypt plantations. Forest Ecology and Management 301:6-27 DOI 10.1016/j.foreco.2012.12.030.

Grosman AH, Breemen MV, Holtz A, Pallini A, Rugama AM, Pengel H, Venzon M, Zanuncio JC, Sabelis, Janssen A. 2005. Searching behaviour of an omnivorous predator for novel and native host plants of its herbivores: a study on arthropod colonization of eucalyptus in Brazil. Entomologia Experimentalis et Applicata 116:135-142 DOI 10.1111/j.1570-7458.2005.00307.x.

Guedes RN, Zanuncio TV, Zanuncio JC, Medeiros AGB. 2000. Species richness and fluctuation of defoliator Lepidoptera populations in Brazilian plantations of Eucalyptus grandis as affected by plant age and weather factors. Forest Ecology and Management 137:179-184 DOI 10.1016/S0378-1127(99)00326-6.

Huerta A, Faundez M, Araya JE. 2010. Susceptibility of Eucalyptus spp. to an induced infestation of red gum lerp psyllid Glycaspis brimblecombei Moore (Hemiptera: Psyllidae) in Santiago, Chile. Ciencia e Investigación Agraria 37:27-33.

Kogan M. 1998. Integrated pest management: historical perspectives and contemporary developments. Annual Review of Entomology 43(1):243-27

DOI 10.1146/annurev.ento.43.1.243.

Laudonia S, Magiotta M, Sasso R. 2014. Seasonal occurrence and adaptation of the exotic Glycaspis brimblecombei Moore (Hemiptera: Aphalaridae) in Italy. Journal of Natural History 48:675-689.

Lockwood JL, Gilroy JJ. 2004. The portability of foodweb dynamics: reassembling an Australian eucalypt-psyllid-bird association within California. Global Ecology and Biogeography 13:445-450 DOI 10.1111/j.1466-822X.2004.00116.x.

Oliveira KN, Jesus FM, Silva JO, Espírito-Santo MM, Faria ML. 2012. An experimental test of rainfall as a control agent of Glycaspis brimblecombei Moore (Hemiptera, Psyllidae) on seedlings of Eucalyptus camaldulensis Dehn (Myrtaceae). Revista Brasileira de Entomologia 56:101-105 DOI 10.1590/S0085-56262012005000008.

Paine TD, Millar JG, Hoddle M. 2000. UC scientists apply IPM techniques to new eucalyptus pests. California Agriculture 54(6):8-13 DOI 10.3733/ca.v054n06p8.

Pereira JM, Baldin ELL, Soliman EP, Wilcken CF. 2013. Attractiveness and oviposition preference of Glycaspis brimblecombei Moore in Eucalyptus spp. Phytoparasitica 41:117-124 DOI 10.1007/s12600-012-0268-7. 
Pereira JMM, Zanuncio TV, Zanuncio JC, Pallini A. 2001. Lepidoptera pests collected in Eucalyptus urophylla (Myrtaceae) plantations during five years in Três Marias, State of Minas Gerais, Brazil. Revista de Biologia Tropical 49:1073-1082.

Phillips C. 1992. Lerps insects. Mount Gambier: PIRSA Forestry.

Queiroz DL, Burckhardt D, Majer J. 2012. Integrated pest management of eucalypt psyllids (Insecta, Hemiptera, Psylloidea). In: Larramendy ML, Soloneski S, eds. Integrated pest management and pest control—current and future tactics. Rijeka: InTech, 385-412.

Queiroz DL, Majer J, Burckhardt D, Zanetti R, Fernandez JIR, Queiroz EC, Garrastazu M, Fernandes BV, Anjos N. 2013. Predicting the geographical distribution of Glycaspis brimblecombei (Hemiptera: Psylloidea) in Brazil. Australian Journal of Entomology 52:20-30 DOI 10.1111/aen.12001.

Queiroz-Santana DL, Burckhardt D. 2007. Introduced Eucalyptus psyllids in Brazil. Journal of Forest Research 12:337-344 DOI 10.1007/s10310-007-0035-7.

R Development Core Team. 2011. R: a language and environment for statistical computing. Vienna: R Foundation for Statistical Computing. Available at https:// rproject.org.

Ramirez ALG, Mancera GM, Guerra-Santos JJ. 2003. Análisis del efecto de las condiciones ambientales en la fluctuación poblacional del psílido del eucalipto en el Estado de México. Cuautitlán Izcalli: Editorial Habana.

Rasband WS. 2006. ImageJ. Maryland: US National Institutes of Health, Bethesda. Available at http://rsb.info.nih.gov/ij/.

Reifenrath K, Riederer M, Müller C. 2005. Leaf surface wax layers of Brassicaceae lack feeding stimulants for Phaedon cochleariae. Entomologia Experimentalis et Applicata 115:41-50 DOI 10.1111/j.1570-7458.2005.00242.x.

Ribeiro GT, Zanuncio JC, Couto L, Zanuncio Jr JS. 2001. Eucalypt wood borer, Phoracantha semipunctata Fab. (Coleoptera: Cerambycidae) ocurrence in Minas Gerais and Espirito Santo, Brazil. Revista Árvore 25(3):393-396.

Sharma A, Raman A, Taylor G, Fletcher M. 2013. Nymphal development and lerp construction of Glycaspis sp. (Hemiptera: Psylloidea) on Eucalyptus sideroxylon (Myrtaceae) in central-west New South Wales, Australia. Arthropod Structure \& Development 42:551-564 DOI 10.1016/j.asd.2013.07.005.

Sookar P, Seewooruthun SI, Ramkhelawon D. 2003. The red gum lerp psyllid, Glycaspis brimblecombei, a new pest of Eucalyptus sp. in Mauritius. Réduit, Mauritius: AMAS. Food and Agricultural Research Council 1:327-332.

Sullivan DJ, Daane KM, Sime KR, Andrews-Jr JW. 2006. Protective mechanisms for pupae of Psyllaephagus bliteus Riek (Hymenoptera: Encyrtidae), a parasitoid of the redgum lerp psyllid, Glycaspis brimblecombei Moore (Hemiptera: Psylloidea). Australian Journal of Entomology 45:101-105 DOI 10.1111/j.1440-6055.2006.00496.x.

Valente C, Hodkinson I. 2009. First record of the red gum lerp psyllid, Glycaspis brimblecombei Moore (Hem.: Psyllidae), in Europe. Journal of Applied Entomology 113:315-317 DOI 10.1111/epp.12014. 
VanLenteren JC, Babendreier D, Bigler F, Burgio G, Hokkanen HMT, Kuske S, Loomans AJM, Menzler-Hokkanen I, Van Rijn PCJ, Thomas MB, Tommasini MG, Zeng QQ. 2003. Environmental risk assessment of exotic natural enemies used in biological control. Biological Control 48:3-38.

Wilcken CF, Couto EB, Orlato C, Ferreira-Filho PJ, Firmino DC. 2003. Ocorrência do psilídeo-de-concha (Glycaspis brimblecombei) (Hemiptera: Psyllidae) em florestas de eucalipto do Brasil [Occurrence of red gum lerp psyllid (Glycaspis brimblecombei) (Hemiptera: Psyllidae) in eucalyptus forests in Brazil]. Informe Técnico do Instituto de Estudos em Pesquisa Agropecuária 201, Botucatu, Brasil. Available at http://www. ipef.br/publicacoes/ctecnica/nr201.pdf.

Zanetti R, Zanuncio JC, Mayhé-Nunes AJ, Medeiros AGB, Souza-Silva A. 2003. Combate sistemático de formigas-cortadeiras com iscas granuladas, em eucaliptais com cultivo mínimo [Systematic control of leaf-cutting ants in areas with eucalyptus stands under minimum cultivation system]. Revista Árvore 27:387-392 DOI 10.1590/S0100-67622003000300016.

Zanuncio JC, Guedes RN, Zanuncio TV, Fabres AS. 2001. Species richness and abundance of defoliating Lepidoptera associated with Eucalyptus grandis in Brazil and their response to plant age. Austral Ecology 26(6):582-589 DOI 10.1046/j.1442-9993.2001.01126.x. 